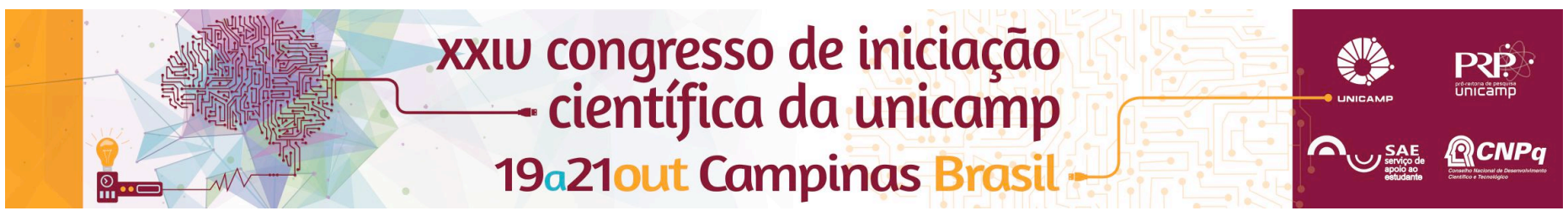

\title{
Caracterização do Raspberry Pi
}

\author{
Pedro De Nigris Vasconcellos*, Lucas Francisco Wanner.
}

\section{Resumo}

Este artigo reporta e analisa os progressos realizados na caracterização do desempenho de 9 benchmarks do Parsec sendo executados na plataforma Raspberry $\mathrm{Pi}$. Os experimentos foram executados em um modelo da segunda geração com o auxílio da ferramenta Perf. Os dados obtidos através do Parsec e do Perf refletem a capacidade elevada de processamento que a plataforma atinge em aplicaçõees de alto nível na proporção em que seus quatro núcleos assim como dados esclarecedores a respeito dos contadores de CPU. A próxima etapa consiste em caracterizar o gasto energético e com base nessa informação implementar bibliotecas que alteram a qualidade dos dados em tempo de execução a fim de minimizar o gasto energético.

\section{Palavras-chave}

Desempenho, Parsec, Raspberry Pi.

\section{Introdução}

$\mathrm{Na}$ última década, tornou-se insustentável aumentar a taxa de processamento sem que o consumo de energia e dissipação de calor mantivessem níveis manejáveis, acarretando no desenvolvimento de paralelização e múltiplos núcleos. Contudo, percebe-se que tecnologias relacionadas à conceitos energéticos foram negligenciadas em prol de desempenho. É necessário considerar outras soluções energicamente viáveis e inteligentes e uma delas advém de plataformas eficientes, que carregam os conceitos de baixo consumo de energia com considerável poder de processamento. Neste ponto consideramos o Raspberry $\mathrm{Pi}$ como esta solução: extremamente versátil, pois oferece funcionalidades semelhantes à de um Desktop em uma máquina do tamanho de um cartão de crédito e com consumo de energia, em média, de $2 \mathrm{~W}$.

Com isso em mente, e considerando que esta plataforma apresenta uma literatura bastante escassa no que se trata dessas capacidades de lidar com aplicações com aplicações de alto desempenho, temos com objetivo principal obter indicadores capazes de apontar vantagens e desvantagens referentes ao Raspberry $\mathrm{Pi}$ a estas aplicações.

\section{Resultados e Discussão}

Utilizamos um Raspberry Pi 2 Model B, processador de 900MHz quad-core ARM Cortex-A7 CPU, 1GB de RAM com o sistema operacional Jessie, baseado no Debian Jessie.

A caracterização se deu exclusivamente através de 9 benchmarks da suíte Parsec' ${ }^{1}$. A fim de testar a escalabilidade e eficiência de processamento, foram utilizadas até 4 threads (número de núcleos ativos).

Os resultados comprovam claramente o ganho de desempenho providenciado pelo multithreading, com melhoras de pelo menos $50 \%$ em todos os benchmarks. Vale ressaltar que este ganho é extramemente significativo vide a natureza das aplicações do Parsec ${ }^{2}$. A ferramenta Perf foi responsável por providenciar valores dos contadores de desempenho de CPU e assim indispensável para detectar disparidades e detalhes específicos das aplicações, evidenciado pela Figura 2, o contador iTLB-load-misses implica que esta aplicação possuem um grande número de instruções tal que a cache não consegue armazenar por completo todos os trechos, resultado no aumento do miss rate da iTLB.

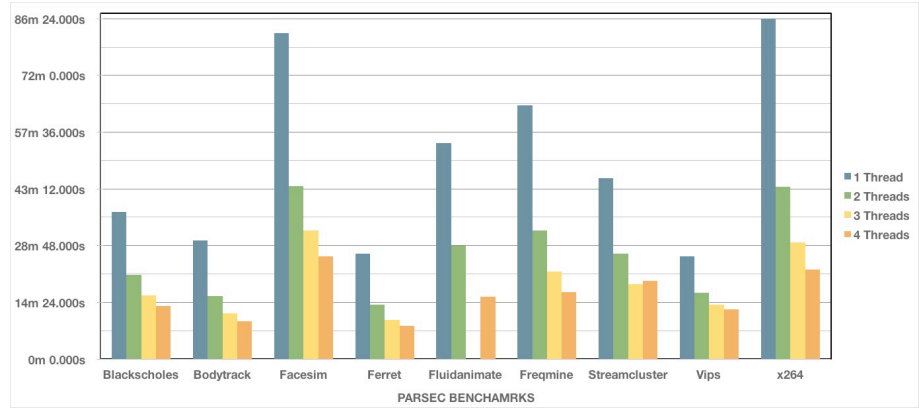

Figura 1. Médias de tempo real para os 9 benchmarks variando o número de threads ativas.

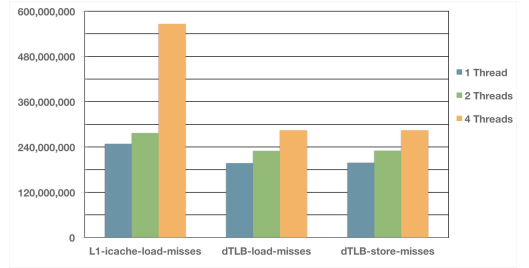

Figura 2. Contadores de CPU do Fluidanimate.

\section{Conclusões}

Estes resultados provam a capacidade do Raspberry Pi em lidar com aplicações que exigem alto nível de processamento garantindo tempo máximo de execução de 30 minutos. Também foi constatado a influência do número de núcleos ativos, representando ganhos de desempenho que variam de $50 \%$ até $74 \%$.

\section{Agradecimentos}

Agradeço à Universidade Estadual de Campinas, ao CNPq, ao Instituto de Computação e ao meu orientador, Lucas Wanner, pela oportunidade de realizar uma pesquisa de Iniciação Científica.

1 MCKINLEY; BLACKBURN; E. Looking back on the language and hardware revolutions: In Measured Power, Performance, and Scaling. 2011.

${ }^{2}$ BIENIA, C. Benchmarking Modern Multiprocessors. PhD thesis, Princeton University. 2011. 